\title{
Body composition changes in haemodialysis patients with secondary hyperparathyroidism after parathyroidectomy measured by conventional and vector bioimpedance analysis
}

\author{
B. S. E. Peters ${ }^{1}$, V. Jorgetti ${ }^{2}$ and L. A. Martini ${ }^{1} *$ \\ ${ }^{1}$ Nutrition Department, School of Public Health, Sao Paulo University, Av. Dr. Arnaldo, 715, Cerqueira César, CEP 01 246-904, \\ São Paulo, Brazil \\ ${ }^{2}$ Nephrology Department, Medicine School, Sao Paulo University, Av. Dr. Arnaldo, 455, Cerqueira César, CEP 01 246-903, São \\ Paulo, Brazil
}

(Received 28 June 2005 - Revised 23 September 2005 - Accepted 27 September 2005)

\begin{abstract}
Considering the negative effects of secondary hyperparathyroidism (SHPT) in patients with chronic renal failure (CRF), the objective of the present study was to evaluate body composition changes using conventional and vector bioimpedance analysis in patients before and after parathyroidectomy (PTX). Twelve adult patients, mean age 43.4 (SD 12.7) years, were evaluated prior to and 6 months after PTX. Diets were assessed with $3 \mathrm{~d}$ dietary records, and mean energy, protein, calcium and phosphorus intake were estimated from these inventories. Weight, height, BMI and bioelectrical impedance were measured; and biochemical markers of nutritional status (albumin and total protein) and bone metabolism (calcium, phosphorus and intact parathyroid hormone) were determined. No significant differences were observed in mean energy, protein and phosphorus after surgery. There was a significant increase in calcium intake after PTX (382.3 (SD 209.6) mg to 656.6 (SD 313.8) mg; P<0.05). Mean weight, BMI, conventional bioelectrical impedance measurements, total body fat, lean body mass and total body water were unaffected by surgery. However, the phase angle and reactance significantly increased after PTX (5.0 (SD 1.4) to 5.6 (SD 1.3); 44.1 (SD 15.6) $\Omega$ to 57.1 (SD 14.4) $\Omega$, respectively). The high levels of intact parathyroid hormone before surgery had a negative effect on total body fat $(r-0.69, P<0 \cdot 05)$. After PTX, the mean albumin significantly increased (3.9 (SD 0.4) g/dl to 4.2 (SD 0.6$) \mathrm{g} / \mathrm{dl} ; P<0.05$ ). PTX for SHPT is associated with certain changes in laboratory values, dietary intake and body composition. The latter is best seen with bioimpedance vector analysis.
\end{abstract}

Body composition: Secondary hyperparathyroidism: Bioimpedance vector analysis

Most patients with stage 5 chronic kidney disease develop secondary hyperparathyroidism (SHPT; Francisco, 2004). SHPT is an adaptive response to chronic kidney disease and is associated with disruptions in the homeostatic control of serum phosphorus, calcium and vitamin D. SHPT remains a significant cause of morbidity in patients with chronic renal failure (CRF), with roughly $50 \%$ of patients receiving dialysis developing this form of renal osteodystrophy (Salem, 1997; Amann et al. 1999).

There are multiple clinical manifestations of SHPT including muscle dysfunction, negative cardiac inotropic effects, leucocyte and T-cell dysfunction, increased vascular calcification, elevated rates of fracture, calciphylaxis, osteoarticular pain, pruritus, abnormal taste, loss of appetite and weight loss (Khajehdehi et al. 1999; Cozzolino et al. 2005).

Malnutrition is a significant factor influencing morbidity and mortality in patients with chronic kidney disease, with roughly $40 \%$ of CRF patients on maintenance haemodialysis (Bergström \& Lindholm, 1993; Qureshi et al. 2002) showing elements of malnutrition. Many factors contribute to the malnutrition associated with chronic kidney disease and chronic maintenance dialysis therapy, including decreased energy and protein intake, chronic inflammation, physical inactivity, concurrent acute or chronic conditions or illnesses, and the catabolic stimulus of dialysis itself (Kaysen, 2001, 2004; Kaysen et al. 2001). Furthermore, the persistently high levels of parathyroid hormone may contribute to malnutrition directly: high parathyroid hormone levels promote derangements in protein and energy metabolism, leading to a weight loss, weakness and muscle atrophy (Bacynski et al. 1985; Miroslaw et al. 1988).

The treatment of SHPT includes multiple dietary and pharmaceutical interventions including administration of calcium salts, vitamin D metabolites, calcimimetics, phosphate-binding agents and dietary phosphorus restriction. Surgical interventions such as percutaneous intra-parathyroid glandular ethanol or calcitriol injections, and parathyroidectomy (PTX), are available. The latter is the treatment of choice in patients 
with severe SHPT, and is the main option when other clinical approaches have failed (Jofré et al. 2003).

Nutritional status optimization is essential to the care of dialysis patients. The need for prospective evaluation of body composition is a key element in achieving this goal. Assessment of total body water, lean body mass, fat mass and body cell mass over time is of clinical importance in order to define 'dry weight' accurately and to identify individuals at risk of malnutrition (Dumler \& Kilates, 2000). Several investigators have used bioelectrical impedance in order to evaluate body composition (Chertow et al. 1995; Foster \& Lukasky, 1996; Oldham, 1996). Bioelectrical impedance analysis (BIA) is a non-invasive, simple and reproducible technique to evaluate changes in body composition. The BIA parameters resistance $(R)$, reactance $(X c)$ and phase angle closely correlate with intracellular and extracellular water content, body cell mass, fat free mass and fat mass content (Cooper et al. 2000; Kusher \& Roxe, 2002).

To predict masses and volumes in these various compartments, conventional BIA uses simple or multiple regression equations derived from the study of subjects with normal soft tissue water content $(73 \%)$. Because these algorithms can produce biased estimates of body compartments in patients with CHD, bioimpedance vector analysis (BIVA) has been developed (Piccoli \& Pastori, 2002). BIVA assumes a bivariate distribution of impedance measurements standardized by height $(H)$ and expressed in units of $\Omega / \mathrm{m}$. Values are reported as $R / H$ and $X c / H$ plotted on a diagram called the RXc-graph (Piccoli et al. 1994).

Here, we used BIVA to monitor the changes in body composition of patients with CRF undergoing PTX for SPHT.

\section{Materials and methods}

\section{Subjects}

The study was carried out in the Renal Osteodystrophy Outpatient Clinic at São Paulo University. From March 2002 to April 2004, twelve haemodialysis (seven male, five female) patients with SHPT were evaluated. Nutritional and biochemical data were measured before PTX and 6 months after surgery. Patients who had recent infections, were being treated for latent tuberculosis, had gastrointestinal diseases, chronic alcoholism, malignant diseases, coronary artery disease or chronic obstructive pulmonary disease; or used mineralocorticoids and anabolic agents were excluded. Patients who received kidney transplants were also excluded.

Dialysis was performed three times, $4 \mathrm{~h}$ weekly. Dialysis protocols were adjusted to the $\mathrm{Kt} / \mathrm{V}$, the dialysate calcium was $2.5 \mathrm{mEq} / \mathrm{l}$ before PTX and $3.5 \mathrm{mEq} / \mathrm{l}$ after PTX. Phosphate binders (calcium carbonate or sevelamer) and calcitriol were used by all patients according to the clinical status before the PTX. After PTX the calcium carbonate was used as a supplement (after the meals). No patients received calcimimetics at the onset of the study.

\section{Nutritional assessment}

Dietary records ( $3 \mathrm{~d})$ were recorded in order to estimate mean energy, protein, calcium and phosphorus intake. Patients completed detailed dietary records before and after surgery.
Nutwin (São Paulo, SP, Brazil) house software was used to calculate mean nutrient intake. Weight, height, BMI and bioelectrical impedance were measured at the same time, between two haemodialysis sessions. BIA was performed using a bioelectrical impedance analyser (model BIA-101Q; RJL Systems Inc., Detroit, MI, USA). All evaluation was conducted on the patients' right side using the four surface standard electrode (tetrapolar) technique on the hand and foot (Lukaski et al. 1985). $R$ and $X c$ were directly measured in ohms $(\Omega)$ at $50 \mathrm{kHz}$ and $800 \mu \mathrm{A}$. The phase angle (in degrees) was calculated using the following equation:

Phase angle $=($ resistance $/$ capacitance $) \times(180 / \pi)$

RXc-graphs (Fig. 1) were generated with BIVA 2002 (Piccoli \& Pastori, 2002), using a Caucasian undergoing chronic haemodialysis as the reference population (Piccoli, 1998).

\section{Biochemical assessment}

Blood samples were drawn from the patients before and after PTX. Serum intact parathyroid hormone (iPTH; normal range $8-76 \mathrm{pg} / \mathrm{ml}$ ) was measured by using an RIA (ELISA PTH; Cis-Bio International, Gif-sur-Yvette, France). Serum total calcium (normal range $8 \cdot 5-10.5 \mathrm{mg} / \mathrm{dl}$ ) and serum phosphorus (normal range $2.3-4.6 \mathrm{mg} / \mathrm{dl}$ ) were determined with an automated analyser (Auto Analyzer Covas-Integra; Roche,

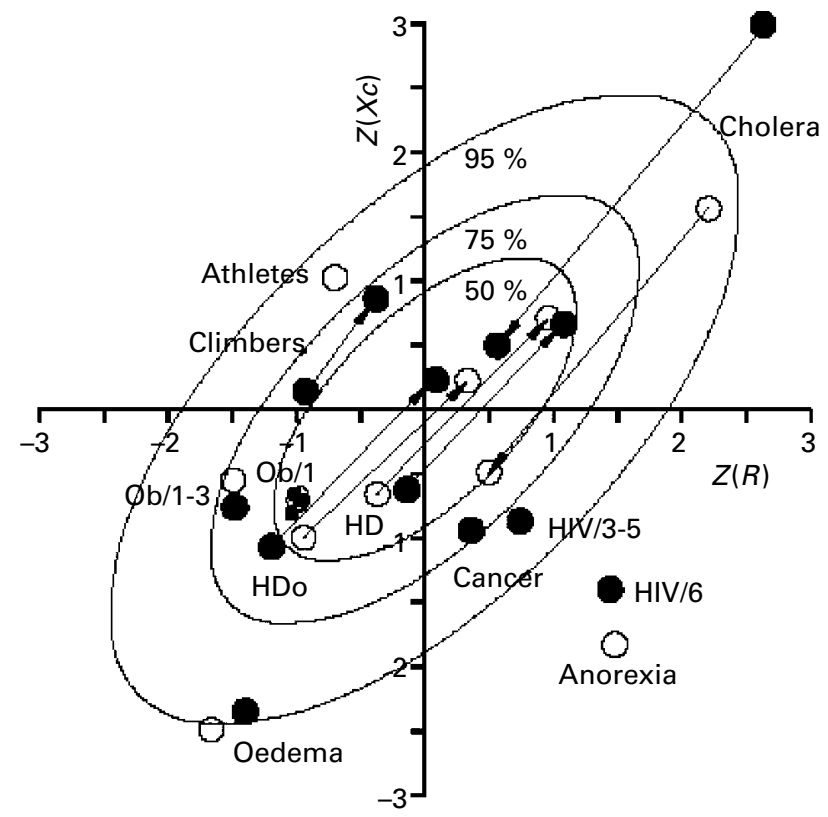

Fig. 1. The reference RXc-graph with $95 \%, 75 \%$ and $50 \%$ tolerance ellipses. Both dimensionless $Z$ scores, i.e. resistance score $Z(R)$ and reactance score $Z(X c)$, are the difference of individual $R$ and $X_{C}$ values from the mean divided by the standard deviation of the reference population. $\bullet$, male; $\mathrm{O}$, female; $\rightarrow$, repeated score vectors from climbers before and after high altitude dehydration, haemodialysis (HD) patients, either lean or obese (HDo) before and after fluid removal with a dialysis session, and dehydrated patients with cholera before and after fluid infusion. Single score vectors are from athletes, obese subjects of class I to III $(\mathrm{Ob} / 1-3)$ or class I (Ob/1) [NHANES III population]. Patients with chronic renal failure (CRF) in conservative treatment, nephrotic syndrome (oedema), lung cancer, AIDS in stage WR 3-5 (HIV/3-5) or WR6 (HIV/6), and anorexia nervosa. 
Table 1. Demographic characteristics, dietary intake and biochemical parameters of haemodialysis patients with secondary hyperparathyroidism*

\begin{tabular}{|c|c|c|c|c|c|}
\hline & \multicolumn{2}{|c|}{$\begin{array}{l}\text { Pre-parathyroidectomy } \\
\qquad(n 12)\end{array}$} & \multicolumn{2}{|c|}{$\begin{array}{l}\text { Post-parathyroidectomy } \\
\qquad(n 12)\end{array}$} & \multirow[b]{2}{*}{$P$} \\
\hline & Mean & SD & Mean & SD & \\
\hline Age (years) & $43 \cdot 4$ & $12 \cdot 7$ & $43 \cdot 4$ & $12 \cdot 7$ & - \\
\hline Time in dialysis (years) & $10 \cdot 6$ & $2 \cdot 8$ & $10 \cdot 6$ & $2 \cdot 8$ & - \\
\hline Height $(\mathrm{cm})$ & $160 \cdot 0$ & $10 \cdot 0$ & $160 \cdot 0$ & $10 \cdot 0$ & - \\
\hline Dry weight (kg) & $57 \cdot 6$ & $17 \cdot 2$ & $57 \cdot 8$ & $18 \cdot 1$ & 0.850 \\
\hline $\mathrm{BMI}\left(\mathrm{kg} / \mathrm{m}^{2}\right)$ & 21.9 & $5 \cdot 1$ & 21.9 & $5 \cdot 5$ & 0.884 \\
\hline \multicolumn{6}{|l|}{ Dietary intakes } \\
\hline Energy [kJ (kcal)/kg per d] & $129.3(30.9)$ & $55 \cdot 6(13 \cdot 3)$ & $146.4(35 \cdot 1)$ & $39.8(9.5)$ & 0.184 \\
\hline Protein $(\mathrm{g} / \mathrm{kg}$ per $\mathrm{d})$ & $1 \cdot 2$ & 0.5 & 1.3 & 0.6 & 0.644 \\
\hline $\mathrm{Ca}(\mathrm{mg} / \mathrm{d})$ & $382 \cdot 2$ & $209 \cdot 6$ & $656 \cdot 6$ & $313 \cdot 8$ & 0.008 \\
\hline $\mathrm{P}(\mathrm{mg} / \mathrm{kg}$ per $\mathrm{d})$ & $13 \cdot 6$ & $6 \cdot 0$ & $17 \cdot 4$ & $6 \cdot 8$ & 0.117 \\
\hline \multicolumn{6}{|l|}{ Biochemical parameters } \\
\hline Total Ca (mg/dl) & $9 \cdot 3$ & $1 \cdot 2$ & 8.5 & $1 \cdot 1$ & 0.091 \\
\hline Inorganic $\mathrm{P}(\mathrm{mg} / \mathrm{ml})$ & $6 \cdot 7$ & 1.8 & 4.5 & 1.5 & $<0.001$ \\
\hline iPTH $(p g / m l)$ & $1221 \cdot 6$ & $685 \cdot 1$ & $153 \cdot 1$ & $189 \cdot 2$ & 0.001 \\
\hline Albumin (g/dl) & 3.9 & 0.4 & $4 \cdot 2$ & 0.6 & 0.047 \\
\hline Total protein (g/dl) & $7 \cdot 0$ & 0.9 & $7 \cdot 6$ & 0.5 & 0.023 \\
\hline
\end{tabular}

iPTH, intact parathyroid hormone.

${ }^{*}$ For details of procedures, see p. 354

Mannheim, Germany). Serum albumin (normal range 3.5$5.0 \mathrm{~g} / \mathrm{dl}$ ) and serum total protein (normal range $6.0-8.0 \mathrm{~g} / \mathrm{dl}$ ) were measured by using a nefelometric biochemical assay. The analyses were performed at the Central Laboratory in the Hospital das Clinicas at São Paulo University.

\section{Statistical analysis}

All results were expressed as means and standard deviations. The variables distribution was analysed by KolmogorovSmirnov test. Since all the variables had normal distributions, the Student's paired $t$-test was performed for comparison of a single mean, and Pearson's correlation was performed for comparison of overall correlation. Hotelling's $T^{2}$ test for paired data was performed for testing the size of change in vector position. $P<0.05$ was considered significant. All calculations were performed using SPSS for Windows, version 11.0 (SPSS Inc., Chicago, IL, USA).

\section{Results}

The demographic characteristics, dietary intakes and biochemical parameters of the twelve subjects are reported in Table 1. All patients were adults and had received dialysis for over 10 years. No significant changes were observed in the dry weight and BMI after PTX. Using the 1995 BMI classification of the WHO, all the patients were well nourished. No statistically significant differences were found in mean energy, protein and phosphorus intake after surgery; however, there was a significant increase in calcium intake after PTX. As expected, the serum phosphorus and the iPTH decreased significantly after PTX. Interestingly, the mean albumin and the total protein significantly increased after PTX.

There were no statistically significant changes in fat body mass, lean body mass, total body water, intracellular or extracellular water after PTX (9.9 (SD 8.1) to 11.6 (SD 8.5) kg, 47.2
(SD 12.8) to 45.5 (SD 14.9) kg, 33.7 (SD 8.9) to 32.2 (SD 9.8) litres, 18.5 (SD 6.5) to 18.9 (SD 6.7) litres, 15.3 (SD 3.5) to $17 \cdot 2$ (SD 10.1) litres, respectively).

There were significant increases in reactance and phase angle (Table 2). Resistance also increased; however, the difference did not reach statistical significance. Unlike conventional measurements, BIVA demonstrates a decrease in total body water, as shown in the RXc-graph (Fig 2) where the vector lengthening of most vectors is apparent in the direction of the major axis of tolerance ellipses, indicating dehydration. The size of change in vector position was significant $\left(T^{2} 9 \cdot 7, P<0 \cdot 05\right)$.

A negative correlation between fat body mass and iPTH was observed before the surgery (Fig 3). However, this correlation was not significant after PTX. No significant correlations were observed between nutrient intakes, lean body mass and serum phosphorus, calcium and iPTH before and after PTX (data not shown).

\section{Discussion}

Inadequate dietary intake is a frequent and important cause of malnutrition in haemodialysis patients. Although it has been

Table 2. Bioimpedance vector analysis parameters and phase angle of haemodialysis patients with secondary hyperparathyroidism*

\begin{tabular}{lrrrrrr}
\hline & \multicolumn{2}{c}{$\begin{array}{c}\text { Pre-parathyroi- } \\
\text { dectomy }\end{array}$} & & \multicolumn{2}{c}{$\begin{array}{c}\text { Post-parathyroi- } \\
\text { dectomy }\end{array}$} \\
\cline { 2 - 3 } & Mean & SD & & Mean & SD & $P$ \\
\hline Resistance $(\Omega)$ & 539.9 & 76.3 & & 612.1 & 117.2 & 0.059 \\
Reactance $(\Omega)$ & 44.1 & 15.6 & & 57.1 & 14.4 & 0.020 \\
Phase angle $\left(^{\circ}\right)$ & 5.0 & 1.4 & & 5.6 & 1.3 & 0.030 \\
$Z(R / H)$ & -0.3 & 1.5 & & 0.8 & 1.6 & 0.049 \\
$Z(X C / H)$ & -2.8 & 1.5 & & -1.9 & 1.6 & 0.096
\end{tabular}

$Z(R / H), Z$-score of resistance/height; $Z(X C / H), Z$-score of reactance/height. ${ }^{*}$ For details of procedures, see p. 354 


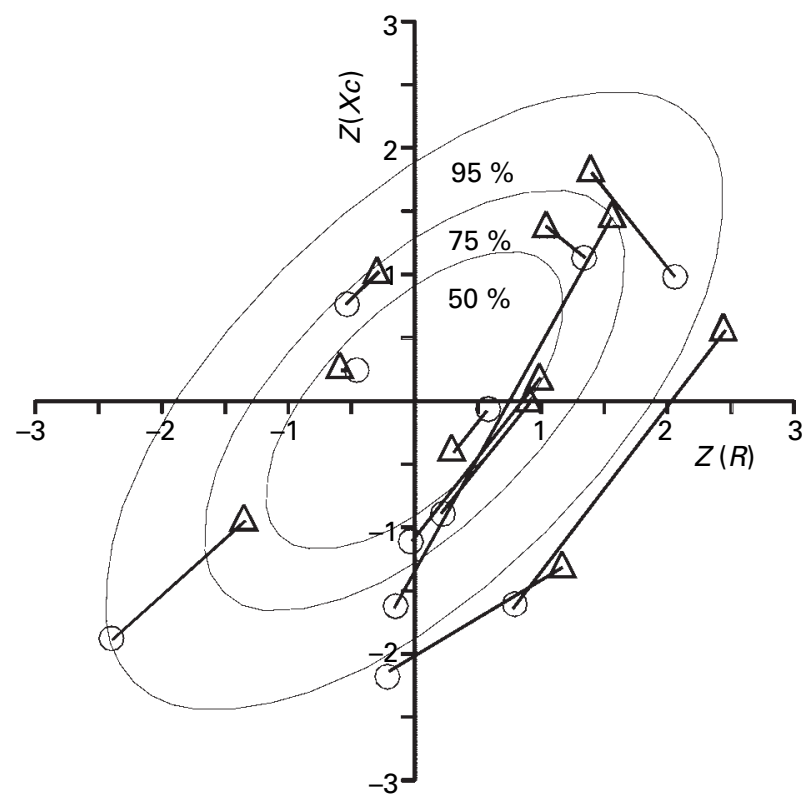

Fig. 2. RXC-graph with $95 \%, 75 \%$ and $50 \%$ tolerance ellipses of haemodialysis patients with secondary hyperparathyroidism. For details of procedures, see $p$. 353. $\triangle$, Pre-parathyroidectomy; $\bigcirc$, post-parathyroidectomy.

hypothesized that inadequate dietary intake might be secondary to uraemia, anorexia, underlying illness, psychosocial conditions, loss of dentures, depression, ageing or chronic inflammation, definitive data on the aetiology of inadequate dietary intake in haemodialysis patients are still lacking. Bossola et al. (2005) investigated dietary intake in thirtyseven patients maintained on regular haemodialysis, and observed that $70.2 \%$ had energy and protein intakes lower than recommended, $18.9 \%$ had adequate energy intake but

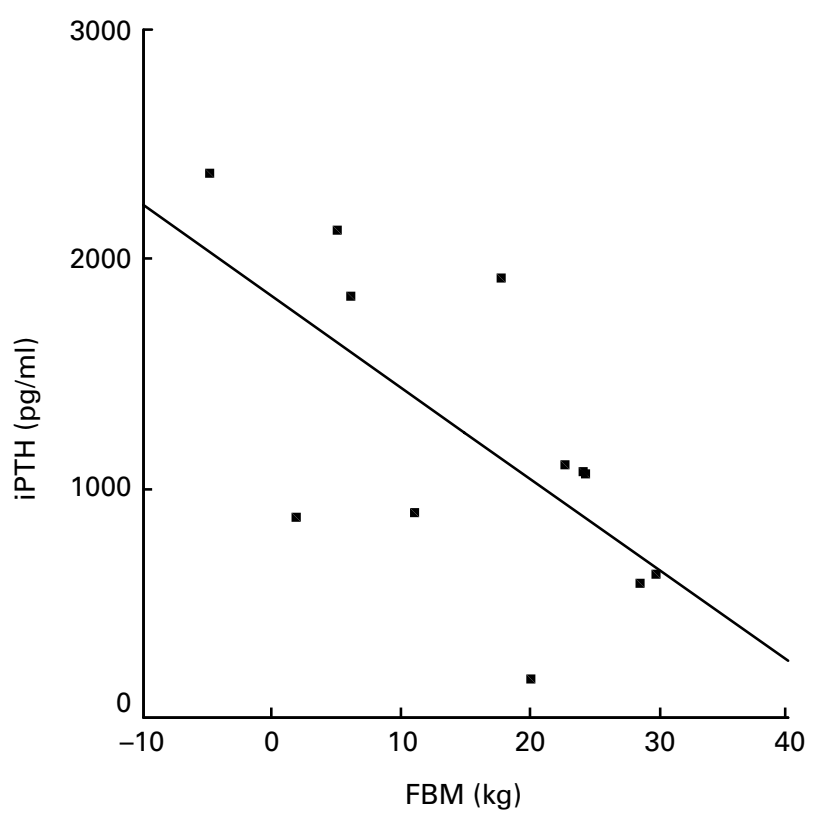

Fig. 3. Scattergram of intact parathyroid hormone (iPTH; pg/ml) versus fat body mass (FBM; $\mathrm{kg}$ ) of haemodialysis patients with secondary hyperparathyroidism before parathyroidectomy. For details of procedures, see p. 354. inadequate protein intake, $2.7 \%$ had adequate protein intake but inadequate energy intake, and only $8.1 \%$ had both adequate energy and adequate protein intake. They also observed that anorexia was present in $53 \%$ of patients with low protein and energy intakes.

The patients studied here had adequate energy, protein and phosphorus intake, while calcium intake was above the recommendations for CRF patients with SHPT (National Kidney Foundation, 2003). The significant increase in calcium intake after PTX may be due to increases in consumption of dairy products, as recommended by nutritionists. The long-term consequences of these changes require further study.

We observed a negative correlation between iPTH and fat body mass before the PTX. Others have found a similar correlation in CRF patients in haemodialysis with moderate and severe SHPT (Peters et al. in press).

Since high parathyroid hormone levels may have deleterious effects on the nutritional status of patients with SHPT, prospective study of patients undergoing PTX is warranted.

We used conventional BIA and BIVA to evaluate body composition changes in CRF patients with SHPT. The reactance and the phase angle significantly increased after PTX, while the conventional BIA parameters did not change. The present findings corroborate a 12-month study showing that there were no significant changes in the conventional BIA parameters (fat mass and lean body mass) while the phase angle decreases significantly (Johansen et al. 2003).

Reactance has been postulated to be an indicator of lean body mass. However, reactance reflects the functional capacity of total body protein stores, and may be a better marker of overall nutritional status than lean body mass (Ikizler et al. 1999). Indeed, we found that albumin and total protein increased significantly after PTX. Similarly, a positive correlation between reactance and nutritional markers like serum prealbumin and albumin has been observed in peritoneal dialysis patients (Mushnick et al. 2003). Chertow et al. (1997a) also reported direct correlations of prealbumin with phase angle and reactance in haemodialysis patients.

Dumler (2003), evaluating 142 patients on chronic dialysis for 12 consecutive months, concluded that overhydration is a contributor to hypoalbuminaemia in these patients. In the present study, the patients presented significant increase in albumin serum and dehydration status after PTX; indicating that the lower albumin levels observed before PTX could be explained in part by a possible overhydration status.

A decline in phase angle indicates a change in body composition, specifically the loss of body cell mass that may occur even in the absence of a change in weight or lean body mass. A likely explanation for such a finding in a dialysis population is that there is an increase in extracelullar fluid that is proportional to a decrease in body cell mass. In other words, dry weight may not have been totally adjusted in response to changes in body composition, due to the improvement in clinical status following PTX.

Furthermore, Chertow et al. (1997b) reported a direct association between survival and phase angle in dialysis patients. Since the survival predictor was not evaluated in our study, the improvement in phase angle after PTX could indicate an increase in body cell mass and nutritional status, hence a better state of overall health. 
In summary, we found that PTX has positive effects on the nutritional status of CRF, and demonstrated that BIVA identifies subtle changes in body composition following PTX that is not seen using conventional BIA. Further study is needed to determine if these changes affect survival of haemodialysis patients.

\section{Acknowledgements}

This study was supported by Conselho Nacional de Desenvolvimento Científico e Tecnológico $(\mathrm{CNPq})$ and Fundação de Amparo à Pesquisa do Estado de São Paulo (FAPESP) (under protocol no. 03/06238-7). The authors would like to thank Wolney Conde Lisboa, PhD for suggestions with BIVA.

\section{References}

Amann K, Gross ML, London GM \& Ritz E (1999) Hyperphosphataemia - a silent killer of patients with renal failure?" Nephrol Dial Transplant 14, 2085-2087.

Bacynski R, Massry SG, Magott M, El-Belbessi S, Kohan R \& Brautbar N (1985) Effect of parathyroid hormone on energy metabolism of skeletal muscle. Kidney Int 28, 722-727.

Bergström J \& Lindholm B (1993) Nutrition and adequacy of dialysis: how do hemodialysis and CAPD compare?" Kidney Int 43, 39S-50S.

Bossola M, Muscaritoli M, Tazza L, Panocchia N, Liberatori M, Giungi S, Tortorelli A, Fanelli FR \& Luciani G (2005) Variables associated with reduced dietary intake in hemodialysis patients. J Ren Nutr 15, 244-252.

Chertow G, Jacobs D, Lazarus J, Lew N \& Lowrie E (1997a) Phase angle predicts survival in hemodialysis patients. J Renal Nutr $\mathbf{7}$, 204-207.

Chertow GM, Lazarus JM, Lew NL, Ma L \& Lowrie EG (1997b) Bioimpedance norms for the hemodialysis population. Kidney Int 52, $1617-1621$.

Chertow GM, Lowrie EG, Wilmore DW, et al. (1995) Nutritional assessment with bioelectrical impedance analysis in maintenance hemodialysis patients. $J$ Am Soc Nephrol 6, 75-81.

Cooper BA, Aslani A, Ryan M, Zhu FY, Ibels LS, Allen BJ \& Pollock CA (2000) Comparing different methods of assessing body composition in end-stage renal failure. Kidney Int $\mathbf{5 8}$, 408-416.

Cozzolino M, Brancaccio D, Gallieni M, Galassi A, Slatopolsky E \& Dusso A (2005) Pathogenesis of parathyroid hyperplasia in renal failure. J Nephrol 18, 5-8.

Dumler F (2003) Hypoalbuminemia is a marker of overhydration in chronic maintenance patients on dialysis. ASAIO J 49, 282-286.

Dumler F \& Kilates C (2000) Use of bioelectrical impedance techniques for monitoring nutritional status in patients on maintenance dialysis. J Renal Nutr 10, 116-124.

Foster KR \& Lukasky HC (1996) Whole-body impedance. What does it measure?" Am J Clin Nutr 64, 388-396.

Francisco AL (2004) Secondary hyperparathyroidism: review of the disease and its treatment. Clin Ther 26, 1976-1993.

Ikizler TA, Wingard RL, Harvell J, Shyr Y \& Hakim RM (1999) Association of morbidity with markers of nutrition and inflammation in chronic hemodialysis patients: a prospective study. Kidney Int 55, 1945-1951.

Jofré R, Goméz JML, Menárguez J, Pólo JR, Guinsburg M, Villaverde T, Flores IP, Carretero D, Benitez PR \& García RP (2003) Parathyroidectomy: whom and when?" Kidney Int 63, S97-S100.

Johansen KL, Kaysen GA, Young BS, Hung AM, da Silva M \& Chertow GM (2003) Longitudinal study of nutritional status, body composition, and physical function in hemodialysis patients. Am J Clin Nutr 77, 842-846.

Kaysen GA (2001) The microinflammatory state in uremia: causes and potential consequences. J Am Soc Nephrol 12, 1549-1557.

Kaysen GA (2004) Inflammation: cause of vascular disease and malnutrition in dialysis patients. Semin Nephrol 24, 431-436.

Kaysen GA, Chertow GM, Adhikarla R, Young B, Ronco C \& Levin NW (2001) Inflammation and dietary protein intake exert competing effects on serum albumin and creatinine in hemodialysis patients. Kidney Int 60, 333-340.

Khajehdehi P, Ali M, Al-Gebory F, Henry G \& Bastani B (1999) The effects of parathyroidectomy on nutritional and biochemical status of hemodialysis patients with severe secondary hyperparathyroidism. J Renal Nutr 9, 186-191.

Kushner RF \& Roxe DM (2002) Bipedal bioelectrical impedance analysis reproducibly estimates total body water in hemodialysis patients. Am J Kidney Dis 39, 154-158.

Lukaski HC, Johnson PE, Bolonchuk WW \& Lykken GI (1985) Assessment of fat-free mass using bioelectrical impedance measurements of the human body. Am J Clin Nutr 41, 810-817.

Miroslaw S, Grazina P, Peggy R, Borum G, Shaul G \& Massry SG (1988) Chronic renal failure, parathyroid hormone and fatty acids oxidation in skeletal muscle. Kidney Int 33, 555-560.

Mushnick R, Fein PA, Mittman N, Goel N, Chattopadhyay J \& Avram MM (2003) Relationship of bioelectrical impedance parameters to nutrition and survival in peritoneal dialysis patients. Kidney Int 83, S53-S56.

National Kidney Foundation (2003) K/DOQI clinical practice guidelines for bone metabolism and disease in chronic kidney disease. Am J Kidney Dis 42, S1-S202.

Oldham NM (1996) Overview of bioelectrical impedance analysers. Am J Clin Nutr 64, 405-412.

Peters BSE, Jorgetti V \& Martini LA (in press) Influência do hiperparatireoidismo secundário grave no estado nutricional de pacientes com insuficiência renal crônica. Rev Nutr.

Piccoli A (1998) Identification of operational clues to dry weight prescription in hemodialysis using bioimpedance vector analysis. Kidney Int 53, 1036-1043.

Piccoli A \& Pastori G (2002a) BIVA Software. Padova: Department of Medical and Surgical Sciences, University of Padova, (available by e-mail from apiccoli@unipd.it).

Piccoli A, Rossi B, Pillon L \& Bucciante G (1994) A new method for monitoring body fluid variation by bioimpedance analysis: the RXc graph. Kidney Int 46, 534-539.

Qureshi AR, Alvestrand A, Divino-Filho JC, Gutierrez A, Heimburger O, Lindholm B \& Bergstrom J (2002) Inflammation, malnutrition, and cardiac disease as predictors of mortality in hemodialysis patients. J Am Soc Nephrol 13, 28S-36S.

Salem MM (1997) Hyperparathyroidism in the hemodialysis population: a survey of 612 patients. Am J Kidney Dis 29, 862-865. 